\title{
30. ISOTOPIC GEOCHEMISTRY OF LAVAS FROM SITES 553 AND $555^{1}$
}

\author{
R. M. Macintyre, Scottish Universities Research and Reactor Centre and University of Strathclyde \\ and \\ P. J. Hamilton, Scottish Universities Research and Reactor Centre ${ }^{2}$
}

\begin{abstract}
It is demonstrated by $\mathrm{K}-\mathrm{Ar}$ analyses that the age of reversely magnetized basalts, which immediately predate magnetic Anomaly 24B, is $53.5 \pm 1.9 \mathrm{~m}$.y. Samples from deep levels appear to be grossly contaminated by an extraneous argon component with a uniform argon- $40 /$ argon-36 ratio $\geq 440$. This component is thought to have been derived from fluids circulating in the lava pile during burial. The age result corroborates the assignment previously made to Anomaly 24B by Hailwood et al. (1979) and Lowrie and Alvarez (1981). It additionally suggests that lava extrusion formed part of a much larger magmatic event, which affected wide areas of the North Atlantic margins around the Paleocene/Eocene boundary, and can therefore probably be considered a good estimate of the age of this boundary. Initial ${ }^{143} \mathrm{Nd} /$ ${ }^{144} \mathrm{Nd}$ ratios lie in the very restricted range $0.512920 \pm 19$ to $0.513026 \pm 24$ and initial ${ }^{87} \mathrm{Sr} /{ }^{86} \mathrm{Sr}$ ratios from ca. 0.703 to ca. 0.705 . Acid leaching reduces the latter range to $0.70264 \pm 4$ to $0.70384 \pm 4$, suggesting that the higher ${ }^{87} \mathrm{Sr} /{ }^{86} \mathrm{Sr}$ ratios resulted from interaction with seawater. The array of data for treated samples is closely conformable on a ${ }^{143} \mathrm{Nd} /$ ${ }^{144} \mathrm{Nd}-{ }^{87} \mathrm{Sr} /{ }^{86} \mathrm{Sr}$ diagram with the main oceanic mantle array and with previously published fields for Atlantic Ocean basalts. No evidence for any continental crustal contamination has been found. This suggests, but does not prove, that continental crust played no part in the genesis of these rocks.
\end{abstract}

\section{INTRODUCTION}

$\mathrm{K}-\mathrm{Ar}, \mathrm{Rb}-\mathrm{Sr}$, and $\mathrm{Sm}-\mathrm{Nd}$ isotopic data have been obtained for basaltic rocks returned from DSDP Leg 81 to assess their age, origin, and the nature of their source region compared with other basalts from the North Atlantic region and possible evidence for any interaction with continental crust. Such information is prerequisite to a proper understanding of the early rifting and onset of spreading. In general the basalts are submarine with many pillows and are interbedded with tuffs, agglomerates, and sediments. At Holes 552A and 554A, only thin basalt sequences were encountered. The samples analyzed in this study were recovered from Sites 553 and 555. They are the seven least-altered samples from over 100 samples which have been analyzed in thin section by Harrison et al. (this volume), namely, two basalts from Site 553 and three basalts and two dolerites from Site 555. For clarity these samples have been simply numbered $\mathrm{A}$ through $\mathrm{G}$. The corresponding DSDP numbers are listed in Appendix A to this chapter.

At Site 553 the lowermost basalts penetrated below the Tertiary sediments correspond to the dipping reflectors, the outer high of which is at the edge of Anomaly 24B. At Site 555 the basalts which are underlain by (intrusive?) olivine dolerites may also represent these reflectors. The basalts are reversely magnetized. Petrographically and chemically they are hypersthene-normative tholeiites. Despite the relative freshness of the samples

\footnotetext{
${ }^{1}$ Roberts, D. G., Schnitker, D., et al., Init. Repts. DSDP, 81: Washington (U.S. Govt. Printingerts,

2 Addresses: (Macintyre and Hamilton) Isotope Geology Unit, Scottish Universities Research and Reactor Centre, East Kilbride, Glasgow G75 0QU; (Macintyre) Department of Applied Geology, University of Strathclyde, Glasgow G1 IXJ.
}

analyzed they have undoubtedly, as shown elsewhere (Harrison et al., this volume), interacted with seawater, and the deepest rocks at Site 555 have experienced greenschist facies alteration.

\section{ANALYTICAL PROCEDURE}

The samples supplied were crushed to small $(\sim 1 \mathrm{~mm})$ fragments, and these were used for argon analyses. A portion of each was ground in a Tema mill and the powders used for the potassium determinations. Further aliquots of the chips were cleaned ultrasonically in distilled water, dried, and ground. The resulting powders were used for $\mathrm{Rb}, \mathrm{Sr}, \mathrm{Sm}$, and $\mathrm{Nd}$ analyses.

Potassium analyses were performed in duplicate by flame photometry on a Corning-Eel Model 450 instrument. A lithium internal standard and sodium buffering were employed. The mean error of the duplicate analyses on the seven samples listed in Table 1 is $0.688 \% \pm$ $0.308(2 \sigma)$. A much more conservative estimate of $\pm 1.5 \%$ has however been assigned to calculate the errors in $\mathrm{K}-\mathrm{Ar}$ age (see footnote, Table 1).

Argon- 40 analyses were performed by fusion in vacuo and gas purification employing (mainly) a Ti-Mo getter. The argon was measured statically by isotope dilution on an MSIO mass-spectrometer. The spike (argon-38, Zurich, 99.99\%) was obtained from a pipette delivering $\sim 8 \times 10^{-7}$ sccs and periodically calibrated against an interlaboratory biotite (BSl33, $4.13 \times 10^{-4} \mathrm{scc} / \mathrm{g}$ ), itself originally calibrated against known volumes of air in this laboratory. The peak heights were corrected for fractionation through the inlet leak valve in a manner similar to that described by Baksi and Farrar (1973). The amplifier ranges were calibrated and peak heights measured manually from a strip chart recorder. Error assignments are listed in the footnote to Table 1 .

Concentrations of $\mathrm{Rb}, \mathrm{Sr}, \mathrm{Sm}$, and $\mathrm{Nd}$ and ${ }^{87} \mathrm{Sr} /{ }^{86} \mathrm{Sr}$ and ${ }^{143} \mathrm{Nd}$ / ${ }^{144} \mathrm{Nd}$ ratios were determined for single dissolutions of $50 \mathrm{mg}$ aliquots of sample powder. In addition separate sample aliquots were leached with $6 \mathrm{M}$ hydrochloric acid and ${ }^{87} \mathrm{Sr} /{ }^{86} \mathrm{Sr}$ ratios determined for the residues and leachates. The $\mathrm{Rb}, \mathrm{Sr}$, and $\mathrm{Sm}$ together with Nd were separated by conventional cation-exchange chromatography and the Sm and Nd further purified following techniques modified from Richard et al. (1976) and Zindler et al. (1979). Concentration determinations by isotope dilution were made on a Vacuum Generators Micromass 30 B mass spectrometer and isotope ratio measurements on a Vacuum Generators Isomass $54 \mathrm{E}$ mass spectrometer. 
Table 1. Exploratory $\mathrm{K}-\mathrm{Ar}$ analyses of samples from Sites 553 and 555 .

\begin{tabular}{cccccc}
\hline Site & Sample & $\begin{array}{c}\mathrm{K} \\
(\mathrm{wt} . \%)\end{array}$ & $\begin{array}{c}40 \mathrm{Ar}^{*} \\
\left(\times 10^{-7} \mathrm{scc} / \mathrm{g}\right)\end{array}$ & $\begin{array}{c}40_{\mathrm{Ar}}^{*} \\
40 \mathrm{Ar}_{\mathrm{T}}\end{array}$ & $\begin{array}{c}\text { "Age" } \\
\text { (m.y.) }\end{array}$ \\
\hline 553 & $\mathrm{~A}$ & 0.041 & 0.854 & 9.44 & $53 \pm 7$ \\
& & 0.041 & 1.001 & 15.5 & $62 \pm 5$ \\
& $\mathrm{~B}$ & 0.054 & 1.864 & 7.64 & $87 \pm 15$ \\
555 & $\mathrm{C}$ & 0.054 & 1.201 & 27.5 & $56 \pm 3$ \\
& & 0.054 & 1.247 & 33.7 & $58 \pm 2$ \\
& $\mathrm{D}$ & 0.051 & 1.224 & 21.7 & $61 \pm 3$ \\
& $\mathrm{E}$ & 0.058 & 2.298 & 5.35 & $99 \pm 26$ \\
& $\mathrm{~F}$ & 0.064 & 2.159 & 7.08 & $85 \pm 16$ \\
& $\mathrm{G}$ & 0.049 & 1.693 & 9.50 & $87 \pm 11$ \\
\hline
\end{tabular}

Note: All samples are basalt with the exception of $\mathrm{E}$ and $\mathrm{G}$ which are dolerites. Corresponding DSDP identification numbers are listed in Appendix A. $\lambda_{\beta}=4.962 \times 10^{-10}$ yr. $^{-1} ; \lambda_{3}=0.581 \times 10^{-10}$ yr. ${ }^{-1} ; 40 \mathrm{~K}=1.167 \times 10^{-2}$ atom \%; errors computed from $\left\{\mathrm{E}_{\mathrm{K}}{ }^{2}\right.$ $\left.+(1+\mathrm{A} / \mathrm{R})^{2} \mathrm{E}_{40}{ }^{2}+\mathrm{E}_{38^{2}}+(\mathrm{A} / \mathrm{R})^{2} \mathrm{E}_{36}{ }^{2}\right\}^{1 / 2}$ where $\mathrm{R}=(100-$ A) $={ }^{40} \mathrm{Ar} * / 40 \mathrm{Ar}_{\mathrm{T}}$ with error in $\mathrm{K}, \mathrm{E}_{\mathrm{K}}=1.5 \%$ and errors in peak heights, $\mathrm{E}_{40}=\mathrm{E}_{38}=0.5 \% ; \mathrm{E}_{36}=1 \%$. The best age derivable from this data for samples A, C, and D is $59.0 \pm 3.1 \mathrm{~m}$.y. (see text). $4 \mathrm{Ar}^{*}=$ radiogenic ${ }^{40} \mathrm{Ar} ;{ }^{40} \mathrm{Ar}_{\mathrm{T}}=$ total ${ }^{40} \mathrm{Ar}$.

\section{RESULTS}

\section{Potassium-Argon Dating}

Since the samples have very low potassium contents and are (relatively) youthful, it was anticipated that some difficulty might be encountered in accurately measuring their small radiogenic argon- 40 concentrations. Complications were also expected since, under these conditions, the presence of any extraneous argon component of nonatmospheric isotopic composition, even in minute concentrations, would render the normal nonradiogenic correction invalid and grossly distort the conventionally calculated ages. A series of preliminary measurements was therefore carried out on small sample aliquots to investigate the possible extent of these problems. The results of these exploratory analyses are presented in Table 1.

It is immediately apparent that many of the conventionally calculated ages are characterized by large uncertainties (as a result of the high nonradiogenic argon- 40 corrections) and many are probably, in addition, anomalous. This seems particularly true for samples B, E, F, $\mathrm{G}$ from the deeper levels at both sites. However the presence of abnormally high total concentrations of both argon- 40 and argon-36 was also revealed in these analyses (cf. Fig. 2; circled points). This is interpreted as indicative of the presence of an extraneous argon component which has a non-atmospheric isotopic composition. No significance is therefore attached to the conventional ages calculated for samples B, E, F, and G. However the data from samples A, C and D in Table 1 can be used to give a first approximation to the age of the uppermost samples. When these are plotted in the manner suggested by York et al., 1969 (see also York and Farquhar, 1972, p. 30), a five-point isochron corresponding to an age of $59.0 \pm 3.1 \mathrm{~m} . \mathrm{y}$. is obtained (see Appendix C).

To determine a more accurate value for the age of the samples and to attempt to investigate more fully the nature and origin of the extraneous argon, a further series of analyses were performed. In these the sample weights were significantly increased and no sample encapsulation was employed. Both measures were aimed at reducing the relative effect of atmospheric argon contamination in an attempt to surmount the problems encountered in the first series of analyses. These results are presented in Table 2.

\section{Rubidium-Strontium and Samarium-Neodymium Results}

Table 3 lists the results of these measurements. The abundances of $\mathrm{Rb}, \mathrm{Sr}, \mathrm{Sm}$, and $\mathrm{Nd}$ are comparable with those of recent Atlantic MORB (e.g., Cohen et al., 1980; Cohen and O'Nions, 1982). The ${ }^{147} \mathrm{Sm} /{ }^{144} \mathrm{Nd}$ ratios are all greater than the average chondritic value of 0.197 (Jacobsen and Wasserburg, 1980) and confirm the light rare earth depleted character of these rocks. No correlations exist between the abundances or abundance ratios of these elements and the isotopic compositions of $\mathrm{Sr}$ and $\mathrm{Nd}$.

\section{Petrogenesis of the Basalts}

The measured ${ }^{87} \mathrm{Sr} /{ }^{86} \mathrm{Sr}$ and ${ }^{143} \mathrm{Nd} /{ }^{144} \mathrm{Nd}$ ratios in Table 3 have been corrected for radioactive decay since 53 m.y. ago (see below), although for Sr the corrections are so small that they are within the limits of error for the measured isotopic ratio. The initial ${ }^{143} \mathrm{Nd} /{ }^{144} \mathrm{Nd}$ ratios are plotted against initial ${ }^{87} \mathrm{Sr} /{ }^{86} \mathrm{Sr}$ ratios on Figure 1 where they can be compared with the data fields (estimated for 53 m.y. ago) for unaltered Atlantic MORB and for basalts from Iceland and the Faeroes. The narrow range of initial ${ }^{143} \mathrm{Nd} /{ }^{144} \mathrm{Nd}$ ratios from $0.513026 \pm$ 24 to $0.51292 \pm 19$ overlaps with the ${ }^{143} \mathrm{Nd} /{ }^{144} \mathrm{Nd}$ ranges for the other data fields shown, as well as with those for continental plateau basalts of Tertiary age from East and West Greenland (Carter et al. 1979).

In contrast, the initial ${ }^{87} \mathrm{Sr} /{ }^{86} \mathrm{Sr}$ ratios range from values typical for Atlantic oceanic basalts (ca. 0.703) up to higher values at ca. 0.705 . The higher ${ }^{87} \mathrm{Sr} /{ }^{86} \mathrm{Sr}$ ratios result in a trend to the right of the anticorrelated array of ${ }^{143} \mathrm{Nd} /{ }^{144} \mathrm{Nd}$ and ${ }^{87} \mathrm{Sr} /{ }^{86} \mathrm{Sr}$ ratios (Fig. 1) documented for unaltered oceanic ridge basalts and some oceanic island basalts (e.g., O'Nions et al., 1977; Richard et al., 1976; DePaolo and Wasserburg, 1976). The effects of the acid leaching procedure on the ${ }^{87} \mathrm{Sr} /{ }^{86} \mathrm{Sr}$ ratios are indicated in Table 3 and Figure 1 . The acid leached samples show a reduction both in the ${ }^{87} \mathrm{Sr} /{ }^{86} \mathrm{Sr}$ ratio and in the range of ${ }^{87} \mathrm{Sr} /{ }^{86} \mathrm{Sr}$ compared with the untreated samples. This results in Figure 1 in a data array more closely conformable with the main oceanic mantle array, although the two deepest samples still retain ${ }^{87} \mathrm{Sr} /{ }^{86} \mathrm{Sr}$ ratios that are relatively high for their respective ${ }^{143} \mathrm{Nd} /$ ${ }^{144} \mathrm{Nd}$ ratios.

\section{INTERPRETATION}

\section{Age of the Basalts and Its Significance}

The argon analyses listed in Table 2 show a considerable decrease in atmospheric argon contamination as compared to those in Table 1. As a result the calculated ages are more precise. Nonetheless they remain mark- 
Table 2. Second series of $\mathrm{K}-\mathrm{Ar}$ analyses of samples A-G.

\begin{tabular}{|c|c|c|c|c|c|c|}
\hline Sample & $\begin{array}{l}\text { Mass } \\
(\mathrm{g})\end{array}$ & $\left({ }_{\left(\times 10^{-1}\right.}{ }^{40}{ }_{\mathrm{moles}} / \mathrm{g}\right)$ & $\frac{{ }^{36} \mathrm{Ar}_{\mathrm{T}}}{\left(\times 10^{-14} \text { moles } / \mathrm{g}\right)}$ & $\begin{array}{c}{ }^{40} \mathrm{Ar}^{*} \\
\left(\times 10^{-12} \text { moles } / \mathrm{g}\right)\end{array}$ & $\frac{{ }^{40} \mathrm{Ar}^{*}}{40 \mathrm{Ar}_{\mathrm{T}}}(\%)$ & $\begin{array}{l}\text { "Age" } \\
\text { (m.y.) }\end{array}$ \\
\hline A & 2.86897 & 1.810 & 4.522 & 4.806 & 26.6 & $66.3 \pm 3.1$ \\
\hline B & 4.12175 & 6.916 & 16.78 & 19.73 & 28.5 & $199 \pm 9$ \\
\hline C & 2.92494 & 1.206 & 2.422 & 4.971 & 41.2 & $52.3 \pm 1.7$ \\
\hline D & 4.47448 & 1.442 & 3.237 & 4.899 & 34.0 & $54.5 \pm 2.0$ \\
\hline E & 4.83465 & 14.72 & 34.83 & 44.71 & 30.4 & $397 \pm 16$ \\
\hline $\mathrm{F}$ & 3.46568 & 4.771 & 11.93 & 12.54 & 26.3 & $110 \pm 5$ \\
\hline G & 4.01371 & 3.768 & 9.658 & 9.223 & 24.5 & $105 \pm 5$ \\
\hline
\end{tabular}

Note: Legend as for Table 1. For interpretation of results see text. Mean age of Samples C and D is $53.4 \pm 1.3 \mathrm{~m} . \mathrm{y}$.

Table 3. Strontium and neodynium isotopic analyses of DSDP samples.

\begin{tabular}{|c|c|c|c|c|c|c|c|c|c|c|}
\hline Sample & $\mathrm{Rb}^{\mathrm{a}}$ & $\mathrm{Sr}^{\mathrm{a}}$ & $\frac{{ }^{87} \mathrm{Rb}}{{ }^{86} \mathrm{Sr}}$ & $\frac{{ }^{87} \mathrm{Sr}^{\mathrm{b}}}{{ }^{86} \mathrm{Sr} \mathrm{I}}$ & $\frac{{ }^{87} \mathrm{Sr}}{{ }^{86} \mathrm{Sr} \mathrm{L}_{\mathrm{L}}}$ & $\frac{{ }^{87} \mathrm{Sr}}{{ }^{86} \mathrm{Sr} \mathrm{R}^{\mathrm{c}}}$ & $\mathrm{Sm}^{\mathrm{a}}$ & $\mathrm{Nd}^{\mathrm{a}}$ & $\frac{147 \mathrm{Sm}}{144 \mathrm{Nd}}$ & $\frac{{ }^{143} \mathrm{Nd}^{\mathrm{b}}}{{ }^{144} \mathrm{Nd} \mathrm{I}}$ \\
\hline A & 0.660 & 66.3 & 0.0288 & $0.70297(4)$ & $0.70308(5)$ & $0.70264(4)$ & 3.10 & 5.70 & 0.329 & $0.513000(16)$ \\
\hline B & 0.725 & 74.3 & 0.0282 & $0.70319(4)$ & $0.70379(4)$ & $0.70266(6)$ & 3.25 & 7.62 & 0.259 & $0.512980(15)$ \\
\hline C & 0.525 & 102 & 0.0148 & $0.70369(4)$ & $0.70459(5)$ & $0.70277(5)$ & 3.83 & 10.6 & 0.218 & $0.512990(26)$ \\
\hline D & 0.612 & 105 & 0.0168 & $0.70329(7)$ & $0.70408(4)$ & $0.70306(5)$ & 3.87 & 10.0 & 0.234 & $0.512920(19)$ \\
\hline E & 0.603 & 86.8 & 0.0201 & $0.70498(4)$ & $0.70582(4)$ & $0.70364(4)$ & 2.17 & 5.79 & 0.227 & $0.512987(22)$ \\
\hline F & 1.05 & 96.1 & 0.0317 & $0.70502(4)$ & $0.70633(5)$ & $0.70360(6)$ & 3.09 & 7.57 & 0.247 & $0.513026(24)$ \\
\hline G & 1.62 . & 74.8 & 0.0627 & $0.70394(5)$ & $0.70439(6)$ & $0.70384(4)$ & 2.19 & 4.15 & 0.319 & $0.513022(18)$ \\
\hline
\end{tabular}

a Concentrations determined by isotope dilution are in ppm and are each determined with a precision of ca. $0.5 \%$.

b Initial ratios calculated for a crystallization age of $53 \mathrm{~m} \cdot \mathrm{y} \cdot \lambda^{87} \mathrm{Rb}=1.42 \times 10^{-11} \mathrm{yr}$. ${ }^{-1} \cdot \lambda^{147} \mathrm{Sm}=6.54 \times 10^{-12}$ yr. ${ }^{-1}$. Errors are $2 \sigma_{\mathrm{m}}$ and correspond to least significant digits. ${ }^{87} \mathrm{Sr} / 86 \mathrm{Sr}$ are normalized to ${ }^{86} \mathrm{Sr} / 88 \mathrm{Sr}=0.1194$ and ${ }^{87} \mathrm{Sr} / 86 \mathrm{Sr}=0.70800$ for Eimer and Amend ${ }^{87} \mathrm{Sr} / 86 \mathrm{Sr}$. ${ }^{143} \mathrm{Nd} / 144 \mathrm{Nd}$ are normalized to ${ }^{146} \mathrm{Nd} /{ }^{144} \mathrm{Nd}=0.7219$.

${ }^{143} \mathrm{Nd} /{ }^{144} \mathrm{Nd}$ for BCR-1 in this laboratory $=0.512633 \pm 10\left(2 \sigma_{\mathrm{m}}, \mathrm{N}=4\right)$

${ }^{c} \mathrm{~L}=$ ratio for $\mathrm{Sr}$ leached with $\mathrm{HCl} ; \mathrm{R}=$ ratio for $\mathrm{Sr}$ residual from $\mathrm{HCl}$ leaching.

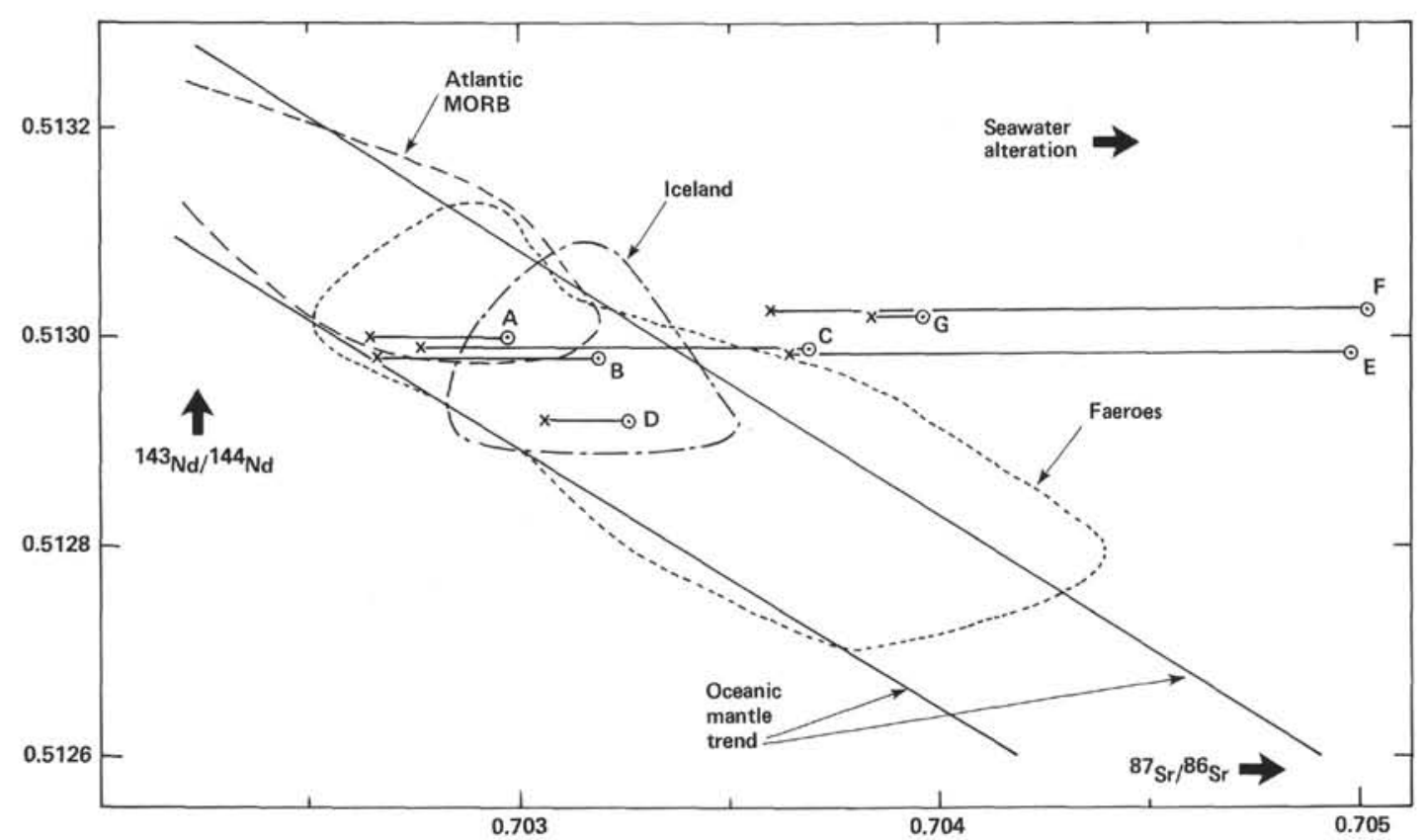

Figure 1. Initial ${ }^{143} \mathrm{Nd} /{ }^{144} \mathrm{Nd}$ and ${ }^{87} \mathrm{Sr} /{ }^{86} \mathrm{Sr}$ ratios for DSDP Leg 81 basaltic samples (circles) compared with the data fields (appropriate for 53 m.y. ago) for unaltered basaltic rocks from the mid-Atlantic ridge, Iceland, and the Faeroes. The reductions in ${ }^{87} \mathrm{Sr} /{ }^{86} \mathrm{Sr}$ ratios following acid leaching are indicated by crosses. Data sources are Carter et al. (1979), Cohen and O'Nions (1982), Cohen et al. (1980), DePaolo and Wasserburg (1976), Dupré and Allègre (9180), Gariépy et al. (1983), O’Nions et al. (1977), Richard et al. (1976), Zindler et al. (1979). 
edly discordant, particularly for samples from the deeper levels.

Table 2 also lists the total argon- 40 and argon- 36 concentrations measured during these analyses. With the exceptions of samples C and D (and possibly A) these are extraordinarily high. This is interpreted as indicating the presence of extraneous argon in these samples. Since there is no guarantee that this argon is of atmospheric composition, no significance is attached to the ages calculated for these samples.

The concentrations of argon- 40 and argon- 36 are seen to be correlated and to increase with depth. The problem of the composition and origin of this extraneous argon is returned to in a later section.

Only the ages of $C$ and D (average $53.4 \pm 1.3 \mathrm{~m} . \mathrm{y}$ ) are considered reliable. These are similar to the youngest fission-track age $(53 \pm 4$ m.y.) measured by Duddy et al. (this volume) at Site 555. Inclusion of these two points in the regression of the data from Table 1 makes little difference to the calculated age. The result of a 7-point regression is $53.5 \pm 1.9$ m.y. (Appendix C). This is considered to be the best estimate of the age.

The samples measured are reversely magnetized and belong to the negative polarity zone which immediately precedes Anomaly 24B. If the preferred age of $53.5 \pm$ 1.9 is accepted as reliable, it provides a new calibration point on the geomagnetic reversal time scale for the lower Tertiary which is independent of glauconites. Indeed it may be regarded as the first direct absolute age measurement of a marine magnetic anomaly.

This new age is identical to that allocated by Hailwood et al. (1979) to the beginning of Anomaly 24B, when this age is recalculated using new decay constants and abundances of Table 1 (Steiger and Jäger, 1977). It is also compatible with the more recent timescale of Lowrie and Alvarez (1981) which is based on the paleontological dating and magnetostratigraphy of Italian pelagic limestones. In this, Anomaly 24B is assigned to the interval 53.21-53.61 m.y.

On a regional scale the measured age is similar to that of the second phase of lower Tertiary igneous activity recognized by Macintyre et al. (1975). It has already been suggested that this episode also includes the North Sea tuffs (main "ash marker") and East Greenland volcanism (Macintyre et al., 1979). Both of these are now known on biostratigraphic evidence to have occurred at the Paleocene/Eocene boundary (Smythe et al., 1983; Soper, Downie et al., 1976; Soper, Higgins, et al., 1976). It has further been demonstrated that the "ash marker" passes laterally into the Faeroese lavas (Smythe et al., 1983). This extensive igneous activity immediately predates the formation of first oceanic crust in Anomaly 24 minus time. Lowrie and Alvarez (1981) consider the Paleocene/Eocene boundary to be within the negative polarity zone immediately preceding Anomaly 24B (and place this boundary at $54.9 \mathrm{~m} . \mathrm{y}$.). The samples analyzed in this study also belong to this zone. If, as seems probable, they also (like the tuffs and lavas of East Greenland and the Faeroes) form part of this far-reaching paroxysmal igneous event, which heralded the breakup of the North Atlantic, then the age of $53.5 \pm 1.9$ m.y. reported here can, in addition, be considered a measurement of the position of the Palaeocene/Eocene boundary on the geological timescale. This age may be compared with the assignment of ca. 54 m.y. on the 1964 Geological Society Phanerozoic timescale and the 51 m.y. date recently assigned by Odin (1982).

At $50 \mathrm{~m}$.y. ago, seawater would have had a ${ }^{87} \mathrm{Sr} /{ }^{86} \mathrm{Sr}$ ratio of ca. 0.708 (Hart and Staudigel, 1978; Hawkesworth and Elderfield, 1978) and its interaction with basaltic crust during hydrothermal alteration would result in raised and more variable ${ }^{87} \mathrm{Sr} /{ }^{86} \mathrm{Sr}$ in the crust. The ${ }^{143} \mathrm{Nd} /{ }^{144} \mathrm{Nd}$ composition of the basaltic crust would be little affected by such alteration because of the low abundance of $\mathrm{Nd}$ (ca. $3 \mathrm{ng} \cdot 1^{-1}$ ) in seawater (e.g., Piepgras and Wasserburg, 1980). This results in a trend to the right on the ${ }^{143} \mathrm{Nd} /{ }^{144} \mathrm{Nd}$ vs. ${ }^{87} \mathrm{Sr} /{ }^{86} \mathrm{Sr}$ diagram as indicated and as observed for the DSDP Leg 81 data (Fig. 1). The effect of such perturbation of pristine ${ }^{87} \mathrm{Sr} /{ }^{86} \mathrm{Sr}$ may be largely removed by acid leaching as demonstrated by O'Nions and Pankhurst (1976) for altered DSDP Leg 37 basalts and as is evident for some of DSDP Leg 81 samples (Table 3, Fig. 1). The three deepest samples (E, F, G), however, retain relatively high ${ }^{87} \mathrm{Sr} /{ }^{86} \mathrm{Sr}$ after acid leaching. This suggests retention of a marine $\mathrm{Sr}$ isotopic signature in an acid resistant phase(s), which may have formed at the higher temperatures of alteration experienced at these deeper levels (see Harrison et al., this volume).

\section{Nature and Origin of the Extraneous Argon}

Data from Tables 1 and 2 are displayed in Figure 2 in the form of a plot of total argon-40 vs. total argon-36. This graphically illustrates the strong correlation between these parameters referred to previously.

Samples A, C, and D plot toward the origin and scatter about line II with slope $286 \pm 5$ (details of all regression analyses will be found in Appendix C). This is similar to the atmospheric argon- $40 / 36$ ratio. The apparent collinearity results from the approximate equivalences in age and potassium content among these samples and the intercept corresponds roughly with their similar radiogenic argon concentrations (cf. Table 2).

Samples B, E, F, and G also have similar potassium contents and are presumed to be of similar age. They have, however, much higher argon concentrations, here attributed to the presence of extraneous argon. The data from Table 1 plot near line I with slope $304 \pm 2$ which lies slightly above line AR of atmospheric slope. When the relative magnitude of the atmospheric argon contamination is reduced (data from Table 2) the points then define another line III with slope $436 \pm 2$ and negative intercept on the ordinate.

A rudimentary model is proposed to explain these results. This simply envisages that some of the samples, which are of the same age and similar potassium contents, have been contaminated, to a greater or lesser degree, by the incorporation of varying amounts of extraneous argon of fixed isotopic composition. A bulk contamination model of this type is considered to be a 


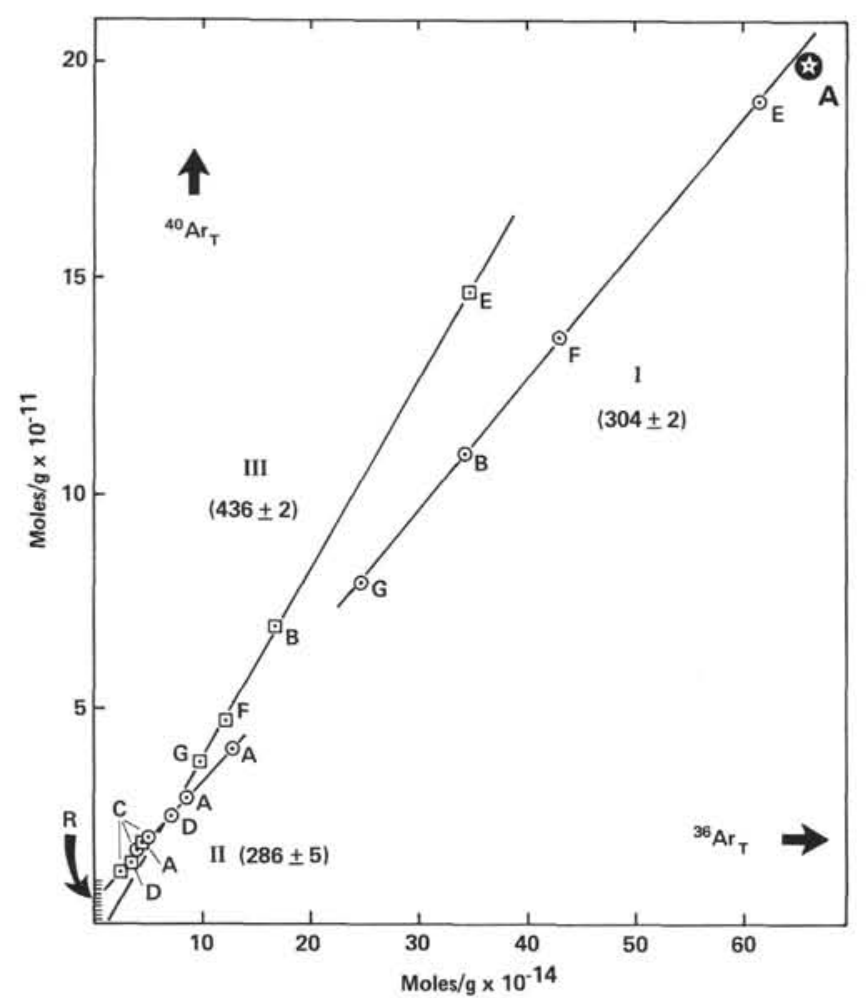

Figure 2. Plot of total argon- 40 vs. total argon- 36 for analyses listed in Table 1 (circles) and Table 2 (squares). $\mathrm{R}$ is "radiogenic point," with intercept corresponding to radiogenic argon- 40 concentration in $53 \mathrm{~m}$.y. rock with $\mathrm{K} \sim 0.05 \%$. AR has slope corresponding to atmospheric argon ratio (295.5); other slopes are given in parentheses. Regression details will be found in Appendix C. The possible significance of this figure is discussed in the text. The slope of line III $(436 \pm 2)$ is regarded as a close approximation to the argon-40/argon- 36 ratio of the extraneous argon in the basalts (B, E, F, G) from the deeper levels.

reasonable representation of the processes extant soon after lava extrusion.

An explanation of the rationale underlying the representation of Figure 2 is given in Appendix B. On the model the collinearity of the data points along line III is regarded as the result of a constant (non-negligible) atmospheric argon contribution. Although the intercept deviates from the radiogenic point $R$, the magnitude of the deviation is small compared to the total volumes of argon-40. Under these conditions the slope of this line is a close approach to the argon-40/argon-36 ratio of the extraneous argon $\left(R_{E}\right)$. An exact determination would require that the atmospheric contamination of $R_{E}$ be eliminated entirely. It can nevertheless be concluded that for the extraneous argon, $R_{E} \gtrsim 440$, considerably higher than the atmospheric value (295.5).

It is considered extremely unlikely that this high $40 / 36$ ratio represents a mantle signature since no pristine phases have been retained in any of the samples analyzed (see Harrison et al., this volume). It is also thought highly improbable that the argon was incorporated in the lavas during extrusion subaerially or on the seafloor, for any argon so introduced would presumably have had atmospheric isotopic composition.
The isotopic ratio appears to be quite uniform over a considerable depth range, but there is a marked increase in argon concentration with depth followed by an apparent decrease (Table 2). This seems to reflect the variation in initial strontium isotopic composition $\left({ }^{87} \mathrm{Sr} /{ }^{86} \mathrm{Sr}\right)_{\mathrm{I}}$ in Table 3. The extraneous argon may therefore also have been derived through interaction with hot fluids (for which there is ample mineralogical and isotopic evidence) circulating in the pile during burial. The source of the argon was presumably earlier-formed K-bearing detrital material in sediments, which degassed as these were dewatered during diagenesis.

The absence of extraneous argon in the rocks from higher levels suggests that the interactions described above did not accompany eruption but occurred during burial soon afterwards. The extraneous argon recognized in these rocks is neither exclusively excess or inherited in the classification of Dalrymple and Lanphere (1969). It is in a sense both.

\section{CONCLUSIONS}

Direct measurement of the $\mathrm{K}-\mathrm{Ar}$ age of samples from Sites 553 and 555 is complicated by the presence of an extraneous argon component whose concentration increases with depth. Nevertheless an age of $53.5 \pm 1.9$ m.y. can be determined for the uppermost samples at Site 555. The extraneous component appears to have an argon-40/argon-36 ratio of $\gtrsim 436$ and to have been derived from sediments and incorporated in the samples from fluids circulating during burial.

The measured age is similar to that of extensive igneous activity around the margins of the North Atlantic. However, it is of additional significance in that it can be regarded as a good estimate of the age of Anomaly 24B on the geomagnetic timescale, and possibly also of the Paleocene/Eocene boundary on the geological timescale. To the best of our knowledge, this is the first direct measurement of the age of a marine magnetic anomaly.

Apart from a marine strontium isotopic signature the results of the trace element and isotopic analyses are very similar to those which have previously been derived for other Atlantic Ocean basalts. No evidence has been found, in any of the rocks analyzed, for any significant contribution of the continental crust to their genesis.

It must again be emphasized that little evidence for crustal contamination has been found from the $\mathrm{Sr}$ and Nd data from some plateau basalts which are demonstrably continental, such as those in East and West Greenland and the Faeroes. In the latter, three silicic basalts with high strontium initial ratios, which are probably the result of continental crustal contamination, have only recently been identified (Haald and Waagstein, 1983; see also caption, Fig. 2). The $\mathrm{Pb}$ isotopic data are, however, indicative of crustal contamination (Gariépy et al., 1983). The $\mathrm{Sr}$ and $\mathrm{Nd}$ isotopic results are therefore equivocal in that they do not necessarily imply the absence of continental crust (or extreme thinning, rapid magma ascent, etc.), although models involving only oceanic crust (e.g., Smythe et al., 1983) perhaps are speculatively favored. We therefore conclude by reiterating (paraphrasing Bradley, 1962) that "there is confusion in any 
reasoning which regards the absence of evidence for continental crust as equivalent to evidence for the absence of continental crust."

\section{ACKNOWLEDGMENTS}

We thank Mr. J. Gray, Mr. J. Jocelyn and Mr. J. Hutchison for technical assistance, Ms. J. Bennett for drafting the figures and Ms. J. McLean for typing. Financial support from the Scottish Universities and N.E.R.C. is gratefully acknowledged.

\section{REFERENCES}

Baksi, A. K., and Farrar, E., 1973. The orifice correction for K-Ar dating. Can. J. Earth Sci., 10:1410-1414.

Bradley, R. D., 1962. Determinism or indeterminism in microphysics. Brit. J. Philos. Sci., 13:215.

Carter, S. R., Evensen, N. M., Hamilton, P. J., and O'Nions, R. K., 1979. Basalt magma sources during the opening of the North Atlantic. Nature, 281:28-30.

Cohen, R. S., Evensen, N. M., Hamilton, P. J., and O'Nions, R. K., 1980. U-Pb, Sm-Nd and $\mathrm{Rb}-\mathrm{Sr}$ systematics of mid-ocean ridge basalt glasses. Nature, 283:149-153.

Cohen, R. S., and O'Nions, R. K., 1982. The lead, neodymium and strontium isotopic structure of ocean ridge basalts. J. Petrol., 23: 299-324.

Dalrymple, G. B., and Lanphere, M. A., 1969. Potassium-Argon Dating: San Francisco (W. H. Freeman and Co.).

DePaolo, D. J., and Wasserburg, G. J., 1976. Inferences about magma sources and mantle structure from variations of ${ }^{143} \mathrm{Nd} /{ }^{144} \mathrm{Nd}$. Geophys. Res. Lett., 3:743-746.

Dupré, B. and Allègre, C. J., 1980. Pb-Sr-Nd isotopic correlation and the chemistry of the North Atlantic mantle. Nature, 286:17-22.

Gariépy, C., Ludden, J., and Brooks, C., 1983. Isotopic and trace element constraints on the genesis of the Faroe lava pile. Earth Planet. Sci. Lett., 63:257-272.

Hailwood, E. A., Bock, W., Costa, L., Dupeuble, P. A., Müller, C., and Schnitker, D., 1979. Chronology and biostratigraphy of northeast Atlantic sediments. In Montadert, L., Roberts, D. G., et al., Init. Repts. DSDP, 48: Washington (U.S. Govt. Printing Office), 1119-1141.

Hald, M., and Waagstein, R., 1983. Silicic basalts from the Faeroe Islands: Evidence of crustal contamination. In Bott, M. H. P., Saxov, S., Talwani, M., and Thiede, J. (Eds.), Structure and Development of the Greenland-Scotland Ridge: London (Plenum Press), 343-349.

Hart, S. R., and Standigel, H., 1978. Oceanic crust: Age of hydrothermal alteration. Geophys. Res. Lett., 5:1009-1012.

Hawkesworth, C. J., and Elderfield, H., 1978. The strontium isotopic composition of interstitial waters from Sites 245 and 336 of the Deep Sea Drilling Project. Earth Planet. Sci. Lett., 40:423-432.

Jacobsen, S. B., and Wasserburg, G. J., 1980. Sm-Nd isotopic evolution of chondrites. Earth Planet. Sci. Lett., 50:139-155.

Lowrie, W., and Alvarez, W., 1981. One hundred million years of geomagnetic polarity history. Geology, 9:392-397.

Macintyre, R. M., McMenamin, T., and Preston, J., 1975. K-Ar results from Western Ireland and their bearing on the timing and siting of Thulean magmatism. Scott. J. Geol. 11:227-249.

1979. Reply to comments of Mussett, A. E. on above. Scott. J. Geol. 15:231-254.

Odin, G. S., 1982. Numerical Dating in Stratigraphy: New York (Wiley).

O'Nions, R. K., Hamilton, P. J., and Evensen, N. M., 1977. Variations in ${ }^{143} \mathrm{Nd} /{ }^{144} \mathrm{Nd}$ and ${ }^{87} \mathrm{Sr} /{ }^{86} \mathrm{Sr}$ ratios in oceanic basalts. Earth Planet. Sci. Lett., 34:13-22.

O'Nions, R. K., and Pankhurst, R. J., 1976. Sr isotope and rare earth element geochemistry of DSDP Leg 37 basalts. Earth Planet. Sci. Lett., 31:255-261.

Piepgras, D. J., and Wasserburg, G. J., 1980. Neodymium isotopic variations in seawater. Earth Planet. Sci. Lett., 50:128-138.

Richard, P., Shimizu, N. and Allègre, C. J., 1976. ${ }^{143} \mathrm{Nd} /{ }^{144} \mathrm{Nd}$, a natural tracer: An application to oceanic basalts. Earth Planet. Sci. Lett., 31:269-278.

Smythe, D. K., Chalmers, J. A., Skuce, A. G., Dobinson, A., and Mould, A. S., 1983. Early opening history of the North AtlanticI. Structure and origin of the Faeroe-Shetland Escarpment. Geophys. J.R. Astr. Soc. 72:373-398.
Soper, N. J., Downie, C., Higgins, A. C., and Costa, L. I., 1976. Biostratigraphic ages of Tertiary basalts on the east Greenland continental margin and their relationship to plate separation in the northeast Atlantic. Earth Planet. Sci. Lett., 32:149-157.

Soper, N. J., Higgins, A. C., Downie, C., Matthews, D. W., and Brown, P. E., 1976. Late Cretaceous-early Tertiary stratigraphy of the Kangerdlugssuaq area, east Greenland, and the age of opening of the north-east Atlantic. J. Geol. Soc. London, 132:85-104.

Steiger, R. H. and Jäger, E., 1977. Subcommission on geochronology: Convention on the use of decay constants in geo- and cosmochronology. Earth Planet. Sci. Lett., 36:359-362.

York, D., Baksi, A. K., and Aumento, F., 1969. K-Ar dating of basalts dredged from the North Atlantic. Trans. Am. Geophys. Union 50: 353. (Abstract)

York, D., and Farquhar, R. M., 1972. The Earth's Age and Geochronology: New York (Pergamon).

Zindler, A., Hart, S. R., Frey, F. A., and Jacobssen, S. P., 1979. Nd and $\mathrm{Sr}$ isotope ratios and rare earth element abundances in Reykjanes Peninsula basalts: evidence for mantle heterogeneity beneath Iceland. Earth Planet. Sci. Lett., 45:249-262.

Date of Acceptance: January 20, 1984

\section{Identification Numbers of Samples}

$\mathrm{A}=$ Sample 553-46-2, 31-33 cm; F8480

$\mathrm{B}=$ Sample 553-49-4, 93-96 cm; F8484

C = Sample 555-69-2, 21-24 cm; glomerophyric basalt: F8497

D = Sample 555-69-4, 85-88 cm; phyric basalt: F8498

$\mathrm{E}=$ Sample 555-76-1, 69-74 cm; dolerite: F8501

$\mathrm{F}=$ Sample 555-90-1,100-104 cm; aphyric basalt: F8504

$\mathrm{G}=$ Sample 555-96-3, 110-113 cm; olivine dolerite: F8508

\section{APPENDIX B \\ Explanation of Figure 2}

As explained in the text, we confine ourselves specifically here to the special case in which the radiogenic argon- 40 concentrations and isotopic composition of the extraneous argon are assumed to be approximately constant among a series of samples.

Let the subscripts T, E, R, and A refer to the total, extraneous, radiogenic, and atmospheric concentrations, respectively. Then in any analysis we have:

and

$$
40_{\mathrm{T}}=40_{\mathrm{E}}+40_{\mathrm{R}}+40_{\mathrm{A}}
$$

$$
36_{\mathrm{T}}=36_{\mathrm{E}}+36_{\mathrm{A}} \text {. }
$$

Also let

$$
\mathrm{R}_{\mathrm{E}}=\frac{40_{\mathrm{E}}}{36_{\mathrm{E}}} \text { and } \mathrm{R}_{\mathrm{A}}=\frac{40_{\mathrm{A}}}{36_{\mathrm{A}}}(=295.5)
$$

then

$$
40_{\mathrm{T}}=36_{\mathrm{E}} \mathrm{R}_{\mathrm{E}}+40_{\mathrm{A}}+40_{\mathrm{R}}
$$

i.e.,

$$
40_{\mathrm{T}}=366_{\mathrm{T}} \mathrm{R}_{\mathrm{E}}-\left(\frac{\mathrm{R}_{\mathrm{E}}}{\mathrm{R}_{\mathrm{A}}}-1\right) 40_{\mathrm{A}}+40_{\mathrm{R}} .
$$

In Figure 2, we plot $40_{\mathrm{T}}$ vs. $36_{\mathrm{T}}$. We first recognize the two extreme cases, that is:

1. If $R_{E}=R_{A}$, the points will lie on straight line with slope $=R_{A}$ and intercept $40_{R}$ on $40_{T}$ - axis (point " $R$ " on Fig. 2).

2. If $40_{\mathrm{A}}=0$ the points are again collinear and the line passes through " $R$," but this time the slope is $R_{E}$.

In intermediate cases, where neither of these conditions is satisfied, a straight line will again result as long as the second term on the RHS is essentially constant, i.e., if $40_{A}$ is constant. If additionally this term is small in comparison to $40_{\mathrm{T}}$, the slope of the line will be a good approximation to the ratio, $R_{E}$. Unless $R_{E}$ is exceptionally large, this latter assumption is equivalent to assuming that $40_{\mathrm{A}}$ is small. Thus, in these intermediate cases, the intercept is less than the radiogenic point by an amount equal to $40_{A}\left(R_{E} / R_{A}-1\right)$. The magnitude of this deviation (as compared to $40_{\mathrm{T}}$ ) is therefore a measure of the closeness of approach of the slope to the ratio $R_{E}$. 
For a particular gas-handling system, $40_{\mathrm{A}}$ can usually be quite reliably estimated from general laboratory experience. For a constant line-blank it will be much smaller when the sample mass is increased. The best estimate can sometimes, as in this case, be derived from the analyses of other samples in the suite which contain no extraneous argon. Thus for samples C and D it is readily apparent from Figure 2 and from Table 2 that $40_{\mathrm{A}}\left(=40_{\mathrm{T}}-40_{\mathrm{R}}\right) \simeq 0.8 \times 10^{-11} \mathrm{moles} / \mathrm{g}$ and that this is small in comparison to most measured values of $40_{\mathrm{T}}$ ( $\geq 3.8 \times 10^{-11}$ moles $/ \mathrm{g}$ ).

The slope of the line, which is in any case determined primarily by the data points with high $40_{\mathrm{T}}^{\mathrm{T}}$, can therefore in this case be considered to be a good approximation to the isotopic composition of the extraneous argon (i.e., $R_{E} \geq 436$ ). This permits evaluation of the extraneous argon- 36 concentrations ( $36_{\mathrm{E}}$ ) since the argon- 40 concentrations $\left(40_{\mathrm{E}}\right)$ are known $\left(=40_{\mathrm{T}}-40_{\mathrm{R}}-40_{\mathrm{A}}\right)$.

Alternative approach. In the previous construct, as $\mathrm{R}_{\mathrm{E}}$ increases so also does the slope and the departure of the intercept from the radiogenic point. The presence of a (constant) $40_{A}$ means that the measured slope $<R_{E}$ and the closeness of approach is governed by the relative magnitude of the atmospheric contamination. This is least for points with high $40_{T}$ and $36_{\mathrm{T}}$. If we take one such point (e.g., E on Fig. 2) and constrain a line of slope $m$ through this point, such that its intercept differs from the radiogenic point by an amount $40_{A}\left(m / R_{A}-1\right)$, then $m$ should be a very good approximation to $R_{E}$.

It is a relatively simple matter to show that this condition is fulfilled if $m$ satisfies $\left(1-f_{36}\right) m=m_{R}-f_{40}$, where $m_{R}$ is the slope of the join to the radiogenic point, $R, f_{36}=36_{A} / 36_{T}$ and $f_{40}=40_{A} / 36_{T}$

As before, for small values of $f, m=m_{R}$. Usually $f_{40} \ll m_{R}$, and so for small values of $f$, the slope which best corresponds to the ratio $R_{E}$ is given by $m=m_{R} / 1-f_{36}$. This demonstrates the critical depen- dence of $m$ on the magnitude of the atmospheric argon-36 contamination.

Considering analysis $\mathrm{E}$ in Figure 2 and Table 2 and again assuming that $40_{\mathrm{A}} \sim 8 \times 10^{-12}$ moles $/ \mathrm{g}$, then $\mathrm{f}_{36} \sim 0.076$ and $\mathrm{m}_{\mathrm{R}}=409$. Thus $R_{E} \simeq m=443$, which is close to the value derived previously.

It is perhaps also worth noting that the above conclusions regarding the isotopic composition of the extraneous argon require no a priori knowledge of the age or potassium content of the samples (only an approximate equivalence of their radiogenic argon- 40 concentrations). Thus if the same, albeit rather unique, circumstances can be assumed, this simple graphical approach might prove useful when these parameters are unknown or difficult to measure, e.g., in a suite of contemporaneous oceanic basaltic glasses.

APPENDIX C

Details of Regression Analyses

\begin{tabular}{lcccccc}
\hline Line & $\begin{array}{c}\text { No. of } \\
\text { points }\end{array}$ & $\begin{array}{c}\text { Error } \\
\text { X }(\%)\end{array}$ & $\begin{array}{c}\text { Error } \\
\text { Y }(\%)\end{array}$ & $\begin{array}{c}\text { Slope } \\
\text { and error }\end{array}$ & $\begin{array}{c}\text { Intercept } \\
\text { and error }\end{array}$ & MSWD \\
\hline I & 4 & 1 & 0.5 & $304 \pm 2$ & $0.50 \pm 0.06$ & 0.09 \\
II & 8 & 1 & 0.5 & $286 \pm 5$ & $0.52 \pm 0.02$ & 2.46 \\
I + II & 12 & 1 & 0.5 & $300 \pm 3$ & $0.47 \pm 0.02$ & 4.58 \\
III & 4 & 1 & 0.5 & $436 \pm 2$ & $-0.44 \pm 0.03$ & 0.12 \\
IV & 5 & 2 & 0.5 & $59.0 \pm 3.1$ & $295 \pm 3$ & 2.90 \\
V & 7 & 2 & 0.5 & $53.5 \pm 1.9$ & $295 \pm 3$ & 2.79 \\
\hline
\end{tabular}

Note: All analyses carried out following method of York (1969). X (\%) and Y (\%) are blanket errors assigned to coordinates. Errors on ages and intercepts are scatter errors $(1 \sigma)$. For IV and V slope is presented as age in m.y. 